\title{
Short-term outcome after cystectomy: comparison of early oral feeding in an enhanced recovery protocol and feeding using Bengmark nasojejunal tube
}

\author{
C. S. Voskuilen ${ }^{1,2}$ - E. E. Fransen van de Putte ${ }^{2}$. J. Bloos-van der Hulst ${ }^{2} \cdot$ E. van Werkhoven ${ }^{3} \cdot$ W. M. de Blok ${ }^{1}$. \\ B. W. G. van Rhijn ${ }^{2} \cdot$ S. Horenblas ${ }^{2} \cdot$ R. P. Meijer ${ }^{1,2}$
}

Received: 15 August 2017 / Accepted: 14 November 2017 / Published online: 22 November 2017

(c) The Author(s) 2017. This article is an open access publication

\begin{abstract}
Purpose Cystectomy for bladder cancer is associated with a high risk of postoperative complications. Standardized perioperative protocols, such as enhanced recovery after surgery (ERAS) protocols, aim to improve postoperative outcome. Postoperative feeding strategies are an important part of these protocols. In this two-centre study, we compared complications and length of hospital stay (LOS) between an ERAS protocol with early oral nutrition and a protocol with early enteral feeding with a Bengmark nasojejunal tube.

Methods We retrospectively reviewed 154 consecutive patients who underwent cystectomy for bladder cancer in two hospitals (Hospital A and B) between 2014 and 2016. Hospital A uses an ERAS protocol ( $n=45)$, which encourages early introduction of an oral diet. Hospital B uses a fast-track protocol comprising feeding with a Bengmark nasojejunal tube (Bengmark-protocol, $n=109$ ). LOS and complications according to Clavien classification were compared between protocols. Results Overall 30-day complication rates in the ERAS and Bengmark protocol were similar (64.4 and 67.0\%, respectively; $p=0.463)$. The rate of postoperative ileus (POI) was significantly lower in the Bengmark protocol (11.9\% vs. $34.4 \%$ in the ERAS protocol, $p=0.009$ ). This association remained significant after adjustment for other variables (odds ratio $0.32,95 \%$ confidence interval $0.11-0.96 ; p=0.042$ ). Median LOS did not differ significantly between protocols (10 days vs. 11 days in the ERAS and Bengmark protocols, respectively; $p=0.861$ ).

Conclusions Early oral nutrition in Hospital A was well tolerated. However, the Bengmark protocol was superior with respect to occurrence of POI. A prospective study may clarify whether the lower rate of POI was due to the use of early nasojejunal tube feeding or other reasons.
\end{abstract}

Keywords Bladder cancer $\cdot$ Perioperative care $\cdot$ Enteral feeding $\cdot$ Postoperative complications $\cdot$ Enhanced recovery after surgery

R. P. Meijer

rmeijer6@umcutrecht.nl

1 Department of Urologic Oncology, University Medical Center Utrecht Cancer Center, Utrecht, The Netherlands

2 Department of Urology, The Netherlands Cancer Institute-Antoni van Leeuwenhoek Hospital, Amsterdam, The Netherlands

3 Department of Biometrics, The Netherlands Cancer Institute-Antoni van Leeuwenhoek Hospital, Amsterdam, The Netherlands

\section{Introduction}

Radical cystectomy (RC) for bladder cancer (BC) is associated with a high complication rate. Thirty-day overall complication rates vary from 26 to $78 \%$ with mortality rates of $1.0-4.0 \%$ [1-3]. The most common complications are infectious or gastrointestinal related, with postoperative ileus (POI) as one of the most frequent [4]. POI is an important reason for prolonged length of hospital stay (LOS) after RC [4-6].

In recent years, attempts have been made to improve recovery and reduce LOS by introducing enhanced recovery after surgery (ERAS) programmes. Their objective is to minimize physiologic stress effects in major surgery and 
thereby decrease time to return of normal function. Postoperative feeding strategies are an important part of these protocols and usually comprise oral intake within $24 \mathrm{~h}$ after surgery. In clinical practice, however, perioperative intake differs greatly between ERAS protocols [7, 8].

In the current study, perioperative protocols for RC in two hospitals were compared. Hospital A is an academic hospital with an annual number of 25 cystectomies for BC. Hospital $\mathrm{B}$ is a tertiary national referral cancer hospital. In this hospital, over 60 cystectomies for BC are performed annually. There is a close collaboration between the oncologic urology departments of both hospitals in a multidisciplinary tumor board and in research but their perioperative protocols for RC differ. In Hospital A, the traditional perioperative protocol was replaced by an ERAS protocol in 2014. In this ERAS protocol, oral diet is started the day after surgery, when tolerated by the patient. Hospital B uses a protocol comprising early enteral feeding via a Bengmark nasojejunal tube (Bengmark protocol). The aim of this study was to compare postoperative outcomes and LOS of RC patients in an ERAS protocol comprising early oral nutrition and in a protocol comprising early enteral feeding via a Bengmark tube.

\section{Methods}

All consecutive patients who underwent cystectomy for BC between January 2014 and October 2016 in Hospital A or B were included. Both open and robot-assisted procedures were analysed. Patients who needed an adjunctive procedure (e.g., nephroureterectomy) were excluded. In addition, patients who received an ureterocutaneostomy were excluded, as this procedure does not include bowel surgery. Comorbidity was assessed by the Charlson Comorbidity Index (CCI) [9]. Hospital stay was measured from the day of admission until discharge after RC. Differences in perioperative care between the protocols are highlighted below. An overview of all elements of both protocols is provided in the Appendix.

\section{Preoperative care}

In the ERAS protocol (Hospital A), patients were admitted the morning of surgery. They did not receive bowel preparation. All patients, excluding insulin-dependent diabetics, were administered $400 \mathrm{cc}$ of a carbohydrate rich drink 2-3 h prior to surgery.

In Hospital B, patients were admitted 1 day before surgery to place a nasojejunal feeding tube (Bengmark). This is a self-propelling, auto-positioning post-pyloric feeding tube. In addition, patients in this hospital were treated with selective digestive decontamination (SDD; see Appendix).

\section{Surgery}

Surgical teams of both hospitals were equally trained and experienced. In both hospitals, surgeons adhered to the same surgical techniques for both open radical cystectomy (ORC) and robot-assisted radical cystectomy (RARC) including similar pelvic lymph node dissection templates. In hospital A, patients were operated by one of two staff urologists. In hospital B, patients were operated by one of four staff urologists. In this cohort, RARC was performed by one urologist in hospital A and two urologists in hospital B.

Both protocols used a combination of general and regional anaesthesia, with insertion of a thoracic epidural for postoperative pain management. The ERAS protocol underwent revision regarding epidural analgesia in November 2015, omitting a thoracic epidural in patients undergoing a robot-assisted procedure. Blood loss and operation time were measured.

\section{Postoperative care}

In the ERAS protocol, the nasogastric tube (NGT) was removed directly after surgery. Patients were allowed to try a normal diet on POD 2. Until normal intake was achieved, they were advised to take 1-2 high calorie nutritional drinks $\left(\right.$ Nutridrink $^{\circledR}$ ). To prevent POI, patients were given chewing gum three times a day and magnesium oxide two times a day. Epidural analgesia, if administered, was replaced by nonopioid pain control $48 \mathrm{~h}$ after surgery. Early mobilisation was promoted, aiming for two hours out of bed on POD 1 and at least $6 \mathrm{~h}$ out of bed from POD 2 onwards.

In the Bengmark protocol, the NGT was removed within $24 \mathrm{~h}$ after surgery. Patients started with enteral nutrition at $20 \mathrm{ml} / \mathrm{h}$ via the Bengmark tube on POD 1. On POD 2, enteral nutrition was raised to $40 \mathrm{ml} / \mathrm{h}$ and patients were encouraged to eat soft foods. From day 3 to day 5, enteral nutrition was gradually raised to $60 \mathrm{ml} / \mathrm{h}$ and patients were allowed to eat normally if possible. Enteral nutrition was stopped if normal intake was achieved. Epidural analgesia was stopped on POD 4. Duration of enteral nutrition via the Bengmark tube was recorded. In both protocols, time to removal of NGT and time to last drain removal were recorded. Finally, in both hospitals, patients were discharged if they had met predefined criteria (Appendix).

\section{Complications}

Hospital and outpatient clinical records were reviewed in detail and complications and unplanned readmissions occurring within 30 and 90 days of surgery were recorded. All complications were graded according to the Clavien-Dindo 
grading system [10]. POI was defined as requirement for cessation of an oral intake regime for $>24 \mathrm{~h}$, the need for a NGT and/or absence of bowel function beyond POD4.

\section{Statistical analysis}

Statistical analyses were performed using IBM SPSS Statistics version 21.0. (Armonk, NY, IBM Corp.). Normally and non-normally distributed data were analysed using independent $t$ tests and Mann-Whitney $U$ tests, respectively. Categorical data were analysed using Chi-squared tests. Associations of protocol and surgical factors with the occurrence of complications were determined using univariable logistic regression. Multivariate logistic regression was used to identify independent effect of protocol on POI. Covariates included age, ASA scores, surgical approach and use of epidural analgesia. Statistical significance was defined as a $p$ value $<0.05$.

\section{Results}

\section{Patient characteristics}

In Hospital A, 50 patients were treated in the ERAS protocol versus 121 patients in Hospital B in the Bengmark protocol. Forty-five patients in the ERAS protocol and 109 patients in the Bengmark protocol met our predefined inclusion criteria. Patient characteristics are shown in Table 1. Patients in the ERAS protocol were significantly older than patients in the Bengmark protocol (mean 69.9 and 64.9 years, respectively; $p=0.005$ ) and had higher ASA scores (ASA 3: 28.9 and $11.0 \%$, respectively; $p=0.001$ ). There were significantly more patients in the Bengmark protocol who received neoadjuvant chemotherapy ( $49.5 \%$ vs. $24.4 \%$ in the ERAS proto$\mathrm{col}, p=0.007)$. Furthermore, in the Bengmark group, more patients were previously exposed to pelvic radiation $(23.9 \%$ vs. $8.6 \%$ ERAS-protocol, $p=0.043$ ).

\section{Surgical and postoperative details}

In Table 2, surgical and postoperative details are shown. A robotic approach was used approximately twice as often in the ERAS protocol (64.4\% vs. $27.5 \%$ in the Bengmark proto$\mathrm{col} ; p<0.001)$. Epidural analgesia was used less frequently in the ERAS protocol (64.4\% vs. 99.1\%; $p<0.001)$. Median LOS did not differ significantly (10 days vs. 11 days for ERAS vs. Bengmark, respectively; $p=0.861$ ). Comparing RARC and ORC within the protocols, LOS was shorter in RARC in both the ERAS and Bengmark protocols. This difference between open and robotic surgery was most apparent in the ERAS protocol (9 days vs. 15.5 days for RARC and
Table 1 Patient characteristics

\begin{tabular}{|c|c|c|c|}
\hline & ERAS $(n=45)$ & Bengmark $(n=109)$ & $p$ value \\
\hline \multicolumn{4}{|l|}{ Age, years } \\
\hline Mean $( \pm$ SD) & $69.9(10.0)$ & $64.9(9.9)$ & 0.005 \\
\hline \multicolumn{4}{|l|}{ BMI, $\mathrm{kg} / \mathrm{m}^{2}$} \\
\hline \multirow[t]{2}{*}{ Mean $( \pm$ SD) } & $25.4(4.8)$ & $26.0(3.7)$ & 0.421 \\
\hline & $n(\%)$ & $n(\%)$ & \\
\hline \multicolumn{4}{|l|}{ Sex } \\
\hline Male & $34(75.6)$ & $79(72.5)$ & 0.847 \\
\hline Female & $11(24.4)$ & $30(27.5)$ & \\
\hline \multicolumn{4}{|l|}{ Diabetes } \\
\hline Yes & $7(15.6)$ & $9(8.3)$ & 0.289 \\
\hline No & $38(84.4)$ & $100(91.7)$ & \\
\hline \multicolumn{4}{|c|}{ Charlson Comorbidity Index } \\
\hline 0 & $21(46.7)$ & $70(64.2)$ & 0.117 \\
\hline 1 & $14(31.1)$ & $25(22.9)$ & \\
\hline$\geq 2$ & $10(22.2)$ & $14(12.8)$ & \\
\hline \multicolumn{4}{|l|}{ Diversion type } \\
\hline Bricker & $44(97.8)$ & $86(78.9)$ & 0.009 \\
\hline Neobladder & $1(2.2)$ & $17(15.6)$ & \\
\hline Indiana pouch & 0 & $6(5.5)$ & \\
\hline \multicolumn{4}{|c|}{ T-stage before surgery } \\
\hline$\leq \mathrm{T} 2$ & $28(62.2)$ & $61(56.0)$ & 0.592 \\
\hline$\geq \mathrm{T} 3$ & $17(37.8)$ & $48(44.0)$ & \\
\hline \multicolumn{4}{|c|}{$\mathrm{N}$-stage before surgery } \\
\hline Negative & $38(84.4)$ & $94(86.2)$ & 0.988 \\
\hline Positive & $7(15.6)$ & $15(13.8)$ & \\
\hline \multicolumn{4}{|c|}{ Neoadjuvant chemotherapy } \\
\hline Yes & $11(24.4)$ & $54(49.5)$ & 0.007 \\
\hline No & $34(75.6)$ & $55(50.5)$ & \\
\hline \multicolumn{4}{|c|}{ Previous pelvic radiation* } \\
\hline Yes & $4(8.6)$ & $26(23.9)$ & 0.043 \\
\hline No & $41(91.4)$ & $83(76.1)$ & \\
\hline \multicolumn{4}{|l|}{ ASA score } \\
\hline ASA 1 & $3(6.7)$ & $33(30.3)$ & 0.001 \\
\hline ASA 2 & $29(64.4)$ & $64(58.7)$ & \\
\hline ASA 3 & $13(28.9)$ & $12(11.0)$ & \\
\hline
\end{tabular}

ASA American Society of Anesthesiologists, BMI Body mass index, $S D$ standard deviation

*Salvage cystectomies after radiotherapy included

ORC in the ERAS group, respectively; 10 days vs. 11 days for RARC and ORC in the Bengmark group, respectively).

In the ERAS protocol, the NGT was removed right after surgery in most cases, but $30.4 \%$ of patients required replacement of the NGT. More patients in the ERAS protocol needed total parenteral nutrition (TPN), although the difference was not statistically significant (26.7\% vs. $13.0 \%$ in the Bengmark protocol; $p=0.069)$. Median duration of epidural analgesia was 2 days in the ERAS protocol $(n=29)$ 
Table 2 Surgical and postoperative details

\begin{tabular}{|c|c|c|c|}
\hline & ERAS & Bengmark & $p$-value \\
\hline \multicolumn{4}{|l|}{ Robot-assisted approach, $n(\%)$} \\
\hline No & $16(35.6)$ & $79(72.5)$ & \multirow[t]{2}{*}{$<0.001$} \\
\hline Yes & $29(64.4)$ & $30(27.5)$ & \\
\hline \multicolumn{4}{|l|}{ Epidural analgesia, $n(\%)$} \\
\hline Overall & $29(64.4)$ & $108(99.1)$ & $<0.001$ \\
\hline ORC & $14(87.5)$ & $79(100)$ & 0.027 \\
\hline RARC & $15(51.7)$ & $29(96.7)$ & $<0.001$ \\
\hline \multicolumn{4}{|l|}{ Median duration of surgery, min (range) } \\
\hline Overall & $340(180-510)$ & $243(145-480)$ & $<0.001$ \\
\hline ORC & $240(180-380)$ & $240(145-480)$ & 0.494 \\
\hline RARC & $360(285-510)$ & $285(180-450)$ & 0.001 \\
\hline \multicolumn{4}{|l|}{ Median blood loss, $\mathrm{cm}^{3}$ (range) } \\
\hline Overall & $400(50-2000)$ & $800(10-4900)$ & 0.010 \\
\hline ORC & $850(400-2000)$ & $1100(50-4900)$ & 0.221 \\
\hline RARC & $200(50-900)$ & $125(10-1100)$ & 0.016 \\
\hline \multicolumn{4}{|l|}{ Median LOS, days (range) } \\
\hline Overall & $10(8-79)$ & $11(8-52)$ & 0.861 \\
\hline ORC & $15.5(8-52)$ & $11(8-52)$ & 0.183 \\
\hline RARC & $9(8-79)$ & $10(8-22)$ & 0.752 \\
\hline NGT removal, POD, median (range) & $0(0-8)$ & $1(0-15)$ & $<0.001$ \\
\hline Patients requiring NGT replacement, $n(\%)$ & $14(31.1)$ & $20(18.3)$ & 0.128 \\
\hline Epidural removal, POD, median (range) & $2(1-5)$ & $5(2-11)$ & $<0.001$ \\
\hline Patients with enteral tube feeding, $n(\%)$ & $5(11.4)$ & $103(94.5)$ & $<0.001$ \\
\hline Duration of enteral tube feeding, days, median (range) & $5(4-6)$ & $5(0-26)$ & 0.651 \\
\hline Patients with TPN, $n(\%)$ & $12(26.7)$ & $14(13.0)$ & 0.069 \\
\hline Duration of TPN, days, median (range) & $10(6-28)$ & $7(2-25)$ & 0.039 \\
\hline
\end{tabular}

$L O S$ length of hospital stay, $N G T$ nasogastric tube, $O R C$ open radical cystectomy, $P O D$ postoperative day, $R A R C$ robot-assisted radical cystectomy, $T P N$ total parenteral nutrition compared to 5 days in the Bengmark protocol $(n=103)$ $(p<0.001$.

\section{Complications and readmissions}

In Table 3, complications occurring within 30 days after $\mathrm{RC}$ are shown according to protocol, with multiple complications in some patients. Furthermore, 30-day- and 90-day readmission rates are shown. Overall complication rates were similar (64.4\% vs. $67.0 \%$ for the ERAS and Bengmark protocols, respectively; $p=0.763$ ). The percentage of POI was significantly lower in the Bengmark protocol $(11.9 \%$ vs. $31.4 \%$ in the ERAS protocol; $p=0.009$ ). In univariable logistic analysis, only the Bengmark protocol was significantly associated with a lower risk of POI (odds ratio (OR) $0.30,95 \%$ confidence interval $(\mathrm{CI}) 0.13-0.71 ; p=0.006$ ). This association remained significant after adjusting for age, surgical approach, higher ASA scores and the use of epidural analgesia (OR 0.32, 95\% CI 0.11-0.96; $p=0.042$, Table 4). Readmission rates were higher in the Bengmark group, although the differences were not statistically significant $(p=0.136)$. Urinary tract infection was the most common reason for readmission in both hospitals (data not shown).

\section{Discussion}

Enhanced recovery protocols after RC are widely used and have led to improved overall complication rates and shorter LOS [11]. However, for some individual ERAS components, such as postoperative feeding strategies, evidence from the literature is sparse. In this retrospective study, we compared complications and LOS between an ERAS protocol with early oral nutrition and a protocol with early enteral feeding with a Bengmark nasojejunal tube. The latter was superior with respect to occurrence of POI, while overall complication rates and LOS were similar.

Overall complication rates in our study were in the higher range of earlier reported rates, which vary between 26 and $78 \%$ [1-3]. However, definition and types of reported complications differ between studies and are subject to the thoroughness of registration. Evaluating a specific complication 
Table 3 Complications, return to theatre and readmissions

\begin{tabular}{|c|c|c|c|}
\hline & ERAS $n(\%)$ & Bengmark $n(\%)$ & $p$-value \\
\hline Overall complication rate $\leq 30$ days & $29(64.4)$ & $73(67.0)$ & 0.763 \\
\hline Return to theatre $\leq 30$ days & $8(17.8)$ & $11(10.1)$ & 0.187 \\
\hline \multicolumn{4}{|l|}{ Minor complications $\leq 30$ days $^{\mathrm{a}}$} \\
\hline Ileus & $14(31.4)$ & $13(11.9)$ & 0.009 \\
\hline Urinary tract infection & $5(11.1)$ & $19(17.4)$ & 0.325 \\
\hline Wound infection & $3(6.7)$ & $4(3.7)$ & 0.417 \\
\hline Blood transfusion & $4(8.9)$ & $20(18.3)$ & 0.141 \\
\hline Pneumonia & $6(13.3)$ & $6(5.5)$ & 0.110 \\
\hline Atrial fibrillation & $2(4.4)$ & $3(2.8)$ & 0.630 \\
\hline Delirium & $2(4.4)$ & $6(5.5)$ & 1 \\
\hline \multicolumn{4}{|l|}{ Major complications $\leq 30$ days $^{\mathrm{a}}$} \\
\hline Intestinal suture leakage & $3(6.7)$ & $2(1.8)$ & 0.124 \\
\hline Fascial dehiscence & $4(8.9)$ & $3(2.8)$ & 0.216 \\
\hline Ureteroileal leakage requiring drainage & $5(11.1)$ & $15(13.8)$ & 0.906 \\
\hline Lymphocele requiring drainage & $3(6.7)$ & $5(4.6)$ & 0.253 \\
\hline Pelvic/abdominal abscess & 0 & $1(0.9)$ & 1 \\
\hline Bleeding & 0 & $4(3.7)$ & 0.322 \\
\hline Sepsis & 0 & $6(5.5)$ & 0.181 \\
\hline Pulmonary embolus & $1(2.2)$ & 0 & 0.292 \\
\hline Renal failure & 0 & $2(1.8)$ & 1 \\
\hline Cerebrovascular accident & 0 & $1(0.9)$ & 1 \\
\hline \multicolumn{4}{|l|}{ Clavien grade $\leq 30$ days $^{\mathrm{b}}$} \\
\hline No complications & $16(35.6)$ & $36(33.0)$ & 0.767 \\
\hline I-II & $18(40.0)$ & $40(36.7)$ & \\
\hline$\geq$ III & $11(24.4)$ & $33(30.3)$ & \\
\hline \multicolumn{4}{|l|}{ Clavien grade $31-90$ days $^{\text {b }}$} \\
\hline No complications & $40(88.9)$ & $91(84.3)$ & 0.868 \\
\hline I-II & $3(6.7)$ & $9(8.3)$ & \\
\hline$\geq$ III & $2(4.4)$ & $8(7.4)$ & \\
\hline \multicolumn{4}{|l|}{ Readmissions } \\
\hline Within 30 days & $3(6.7)$ & $17(15.6)$ & 0.134 \\
\hline Within 90 days & $8(17.8)$ & $32(29.4)$ & 0.136 \\
\hline
\end{tabular}

${ }^{a}$ Some patients experienced multiple complications

${ }^{\mathrm{b}}$ If more than one complication occurred in one patient, the highest grade was scored
Table 4 Multivariable logistic regression analysis identifying factors associated with postoperative ileus

\begin{tabular}{llll}
\hline & OR & $95 \%$ CI & $p$ value \\
\hline Bengmark protocol & 0.32 & $0.11-0.96$ & 0.042 \\
Robot-assisted approach & 0.70 & $0.24-2.00$ & 0.500 \\
ASA II & 0.80 & $0.25-2.58$ & 0.710 \\
ASA III & 0.86 & $0.20-3.76$ & 0.840 \\
Epidural analgesia & 0.85 & $0.21-3.45$ & 0.820 \\
Age (increase of 1 year) & 1.05 & $1.00-1.10$ & 0.050 \\
\hline
\end{tabular}

such as POI, our rates are also in the higher range of previous series, specifically considering the POI rate of $31.4 \%$ in the ERAS protocol. In a systematic review, POI incidence after $\mathrm{RC}$ ranged from 1.6 to $23.5 \%$ [4]. However, the definition of POI is highly variable across urologic literature, and therefore, true incidence is hard to determine [12]. In our study, clinical records were reviewed in detail and POI was scored if our strict predefined criteria (see Methods) were met. Nevertheless, when studying POI retrospectively, observation bias cannot be excluded. The higher POI rate in the ERAS protocol may partly be explained by the fact that introduction of a new perioperative protocol (i.e., ERAS) makes caregivers more conscious of complications and LOS. Several previous reports on ERAS protocols have demonstrated this effect $[13,14]$.

Notwithstanding this limitation, it is interesting that we found a lower rate of POI in the Bengmark group. Most ERAS protocols in urologic surgery are adapted from 
protocols in colorectal surgery. In this field, many highquality clinical studies have shown that early oral intake as a route for enteral nutrition is safe and effective [15]. However, these data may not be directly applicable to RC because the construction of a urinary diversion, the uretro-enteric anastomosis, potential urinary leakage and large pelvic dissection differ between RC and colorectal surgery. Early introduction of enteral feeding is inherent to any enhanced recovery protocol because of positive effects on insulin resistance, muscle function and wound healing; the latter being specifically relevant to the integrity of the bowel anastomosis after creation of a urinary diversion [15-17]. Now the question is, which route of enteral nutrition should be preferred. Only one study prospectively reviewed the impact of early oral feeding on complications and LOS after RC [18]. In this randomized trial, patients either received access to liquids and then a regular diet on POD 1 and further $(n=50)$, which is comparable to the ERAS protocol in the current study, or care as usual with introduction of a liquid diet after return of bowel activity $(n=52)$. Although the trial did not meet the enrolment target, no differences in complications (including POI) were found and early oral feeding was well tolerated [18].

Apart from our study, no other studies have evaluated the outcome of early enteral tube feeding in RC patients. Nasojejunal early nutrition was introduced in Hospital B after a meta-analysis of studies in abdominal surgery showed decreased mortality in patients who were fed enterally compared to patients without enteral feeding $[19,20]$. In the literature, no causal relation of nasojejunal enteral feeding and lower ileus rates has been described. We hypothesize that after creation of a urinary diversion, a period of gastroparesis may develop, which may be circumvented by the nasojejunal enteral feeding. Whereas, a lower POI rate may be interpreted as an advantage of the Bengmark protocol, there are downsides to consider. First, despite the fact that the Bengmark tube is an auto-positioning device in the presence of normal gastric motility, it remains an invasive procedure with possible complications. Second, the tube has to be inserted at least $12 \mathrm{~h}$ prior to surgery, because of the time the self-propelling mechanism takes to migrate into the jejunum. Consequently, patients need to be admitted the day before surgery. Finally, feeding tubes cause nasopharyngeal discomfort in the postoperative course.

In our study, the association between the Bengmark protocol and the lower rate of POI was independent of other factors, such as epidural use. Previous studies in colorectal surgery have suggested that postoperative epidural analgesia, in contrast to opiate use, can lead to a decrease in ileus [21]. Further research should be undertaken to investigate the effects of different pain medications on RC patients.

Main limitations of this study are its retrospective character, the limited sample size in one of the arms and the differences in patient and surgical characteristics between the two centers. Since Hospital B is a comprehensive cancer center, more patients in this hospital underwent neoadjuvant chemotherapy or had a history of pelvic radiation. Another difference is due to the surgical approach, with more patients undergoing RARC in the ERAS group. In our study, however, multivariable analysis showed that the association between the Bengmark protocol and POI was independent of surgical approach. This is in line with the results of Bochner et al. Their randomized trial comparing outcome after ORC and RARC, did not show any differences regarding LOS or complication rates [22]. We acknowledge the limitation of comparing perioperative care between two hospitals. However, many aspects of perioperative care (e.g., postoperative nursing care or perioperative anaesthetic care) are difficult to account for and may confound outcomes even within the same hospital or protocol.

In conclusion, this study showed that early oral nutrition in the ERAS protocol was well tolerated. There were no differences in overall complication rates comparing the two protocols. Importantly, the protocol using nasojejunal feeding was superior considering the frequency of POI. However, because of the retrospective study design, conclusions have to be interpreted with caution. A prospective study is needed to determine if the lower rate of POI in the Bengmark group was due to the use of nasojejunal feeding or other reasons.

Authors' contribution CS Voskuilen: Project development, data collection, data analysis, manuscript writing. EE Fransen van de Putte: Data collection, manuscript editing. J Bloos-van der Hulst: Protocol development. E van Werkhoven: Statistical analysis. WM de Blok: Protocol development. BWG van Rhijn: Protocol development, manuscript editing. S Horenblas: Protocol development, manuscript editing. RP Meijer: Project development, protocol development, data collection, manuscript editing.

\section{Compliance with ethical standards}

Conflict of interest The authors declare that they have no conflict of interest.

Open Access This article is distributed under the terms of the Creative Commons Attribution 4.0 International License (http://creativecommons.org/licenses/by/4.0/), which permits unrestricted use, distribution, and reproduction in any medium, provided you give appropriate credit to the original author(s) and the source, provide a link to the Creative Commons license, and indicate if changes were made.

\section{Appendix}

See Table 5. 
Table 5 Overview of pre- intra- and postoperative elements of ERAS and Bengmark protocols

Preoperative care
Counselling
ERAS
Bengmark
Admission
ERAS
Bengmark
Preoperative bowel preparation
ERAS
Bengmark
Preoperative carbohydrate loading
ERAS
Bengmark
Preoperative fasting
ERAS
Bengmark
Premedications
ERAS
Bengmark

Thromboembolic prophylaxis

ERAS

Bengmark

Intraoperative care

Epidural analgesia

ERAS

Bengmark

Antimicrobial prophylaxis

ERAS

Bengmark

Perioperative fluid management

ERAS

Bengmark

Preventing intraoperative hypothermia

\section{ERAS \\ Bengmark}

Preventing PONV

ERAS

Bengmark

Postoperative care

Nasogastric intubation

ERAS
Patient education about procedure by surgeon at preclinical visit together with specific education about ERAS protocol by nurse practitioner. Written information about ERAS protocol provided

Patient education about procedure and Bengmark tube at preclinical visit, together with written information

All patients admitted morning of surgery. Consultation by an enterostomal therapist

All patients admitted 1 day before surgery for consultation by an enterostomal therapist and to place a jejunal feeding tube (Bengmark)

None

None

Carbohydrate rich drink 2-3 h before surgery for all patients (insulin dependent diabetics excluded)

None

Solid foods up to $6 \mathrm{~h}$ before surgery, clear fluids up to $2 \mathrm{~h}$ before surgery, then nil oral intake

Solid foods up to $6 \mathrm{~h}$ before surgery, clear fluids up to $4 \mathrm{~h}$ before surgery, then nil oral intake

Acetaminophen $1000 \mathrm{mg}$ on the day of surgery

Temazepam $10 \mathrm{mg}$ the evening before surgery

Oxazepam $10 \mathrm{mg}$ and acetaminophen $1000 \mathrm{mg}$ day of surgery

SDD: this consisted of the administration of three antibiotics: polymyxin E, tobramycin and amphotericin B. SDD was started the evening before surgery and was given until the first solid oral diet or when enteral feeding exceeded $1 \mathrm{~L}$ after surgery

Start LMWH prophylactic evening before surgery. Compressive stockings and sleeves for $24 \mathrm{~h}$, starting the morning of surgery

Start LMWH prophylactic evening before surgery. Compressive stockings, starting the morning of surgery

Thoracic epidural (Th11/12) in all patients undergoing ORC, since November 2015 omitted in patients undergoing RARC

Thoracic epidural (Th11/12) in all patients

Kefzol $2 \mathrm{~g} /$ Flagyl $500 \mathrm{mg}$ started intravenously just before the operation and continued for $24 \mathrm{~h}$

Kefzol $2 \mathrm{~g} /$ Flagyl $500 \mathrm{mg}$ started intravenously just before the operation and continued for $24 \mathrm{~h}$

Restrictive fluid management

Restrictive fluid management

Upper-body air-warming (Bairhugger)

Warming mattress and warming blanket (WarmTouch)

Depending on PONV-score calculated at preoperative screening: ondansetron $4 \mathrm{mg}$ at the end of surgery

Depending on PONV-score calculated at preoperative screening: dexamethasone $5 \mathrm{mg}$ and/or droperidol $1.25 \mathrm{mg}$

Removal after surgery (in recovery, end of day). 
Table 5 (continued)

\begin{tabular}{|c|c|}
\hline Bengmark & Removal $24 \mathrm{~h}$ after surgery, unless adhesiolysis, nausea or $>1000 \mathrm{ml}$ production \\
\hline \multicolumn{2}{|c|}{ Drain removal } \\
\hline ERAS & Removed on POD 2 (if suspect for urinary leakage, creatinine measurement first) \\
\hline Bengmark & Removed on POD 3 (if suspect for urinary leakage, creatinine measurement first) \\
\hline \multicolumn{2}{|l|}{ Nutrition } \\
\hline ERAS & $\begin{array}{l}\text { POD 0: Start with 1-2 bottles of high calorie nutritional drinks, continue until discharge. Aim for at } \\
\text { least } 800 \mathrm{ml} \text { of oral liquids. POD 1: Light oral diet (bread and liquids). POD 2: Normal oral diet in } \\
\text { the absence of nausea, vomiting or abdominal distension }\end{array}$ \\
\hline Bengmark & $\begin{array}{l}\text { Start with enteral nutrition via Bengmark on POD } 0 \\
\text { First } 6 \mathrm{~h} 42 \mathrm{ml} / \mathrm{h} \text {, second } 6 \mathrm{~h} 65 \mathrm{ml} / \mathrm{h} \text {, after that depending on dietary need as determined by dietician. } \\
\text { Start oral intake depending on peristalsis }\end{array}$ \\
\hline \multicolumn{2}{|c|}{ Prevention of postoperative ileus } \\
\hline ERAS & Magnesium oxide twice daily and chewing gum for $5-45 \mathrm{~min}$ thrice daily \\
\hline Bengmark & Magnesium oxide in some patients, depending on bowel movement. Chewing gum as often as possible \\
\hline \multicolumn{2}{|c|}{ Postoperative analgesia } \\
\hline ERAS & $\begin{array}{l}\text { Stop epidural } 48 \mathrm{~h} \text { after surgery. Acetaminophen } 1000 \mathrm{mg} \text { four times a day starting on POD } 0 . \\
\text { Diclofenac ( } 50 \mathrm{mg} \text { thrice daily) starting before removal of epidural (not in case of impaired renal } \\
\text { function) }\end{array}$ \\
\hline Bengmark & Stop epidural on POD 4. Acetaminophen $1000 \mathrm{mg}$ four times a day starting on POD 0 \\
\hline \multicolumn{2}{|l|}{ Mobilisation } \\
\hline ERAS & POD 1: $2 \mathrm{~h}$ on chair. POD 2: $6 \mathrm{~h}$ on chair \\
\hline Bengmark & Start mobilisation on POD 0, not further specified \\
\hline \multicolumn{2}{|c|}{ Discharge criteria } \\
\hline ERAS & $\begin{array}{l}\text { Normal diet, return of normal bowel function, mobilisation on pre-operative level, able to take care of } \\
\text { urinary diversion, adequate oral pain management }\end{array}$ \\
\hline Bengmark & $\begin{array}{l}\text { Normal diet, return of normal bowel function, mobilisation on pre-operative level, able to take care of } \\
\text { urinary diversion, adequate oral pain management }\end{array}$ \\
\hline
\end{tabular}

$L M H W$ low molecular weight heparine, $O R C$ open radical cystectomy, $P O D$ postoperative day, $R A R C$ robot-assisted radical cystectomy, $S D D$ selective digestive decontamination

\section{References}

1. Shabsigh A, Korets R, Vora KC et al (2009) Defining early morbidity of radical cystectomy for patients with bladder cancer using a standardized reporting methodology. Eur Urol 55:164-176. https://doi.org/10.1016/j.eururo.2008.07.031

2. De Nunzio C, Cindolo L, Leonardo C et al (2013) Analysis of radical cystectomy and urinary diversion complications with the Clavien classification system in an Italian real life cohort. Eur J Surg Oncol 39:792-798. https://doi.org/10.1016/j.ejso.2013.03.008

3. Novara G, Catto JWF, Wilson T et al (2015) Systematic review and cumulative analysis of perioperative outcomes and complications after robot-assisted radical cystectomy. Eur Urol 67:376401. https://doi.org/10.1016/j.eururo.2014.12.007

4. Ramirez JA, McIntosh AG, Strehlow R et al (2013) Definition, incidence, risk factors, and prevention of paralytic ileus following radical cystectomy: a systematic review. Eur Urol 64:588-597. https://doi.org/10.1016/j.eururo.2012.11.051

5. Chang SS, Baumgartner RG, Wells N, Cookson MSSJ (2002) Analysis of early complications after radical cystectomy: results of a collaborative care pathway. J Urol 167:2012-2016. https:// doi.org/10.1016/S0022-5347(05)65074-4

6. Hollenbeck BK, Miller DC, Taub D, Dunn RL, Khuri SF, Henderson WG, Montie JE, Underwood W 3rd, WEI JT (2005) Identifying risk factor for potentially avoidable complications following radical cystectomy. J Urol 174:1231-1237. https://doi. org/10.1097/01.ju.0000173923.35338.99
7. Baack Kukreja JE, Messing EM, Shah JB (2016) Are we doing "better"? The discrepancy between perception and practice of enhanced recovery after cystectomy principles among urologic oncologists. Urol Oncol Semin Orig Investig 34:120.e17-120.e21. https://doi.org/10.1016/j.urolonc.2015.10.002

8. Holzhauer C, Weijerman PC, Smits GAHJ, Wijburg CJ (2016) Enhanced recovery after surgery (ERAS) effectief bij robotgeassisteerde radicale cystectomie (RARC); standaardisatie gewenst. Tijdschr voor Urol. https://doi.org/10.1007/s13629-016-0138-z

9. Charlson M, Szatrowski T, Peterson J, Gold J (1994) Validation of a combined comorbidity index. J Clin Epidemiol 47(11):1245-1251

10. Dindo D, Demartines N, Clavien P-A (2004) Classification of surgical complications. Ann Surg 240:205-213. https://doi. org/10.1097/01.sla.0000133083.54934.ae

11. Tyson M, Chang S (2016) Enhanced recovery pathways versus standard care after cystectomy: a meta-analysis of the effect on perioperative outcomes. Eur Urol 2016:1-9. https://doi. org/10.1016/j.eururo.2016.05.031

12. Donat SM (2007) Standards for surgical complication reporting in urologic oncology: time for a change. Urology 69:221-225. https://doi.org/10.1016/j.urology.2006.09.056

13. Collins JW, Patel H, Adding C et al (2016) Enhanced recovery after robot-assisted radical cystectomy: EAU robotic urology section scientific working group consensus view. Eur Urol 70:649-660. https://doi.org/10.1016/j.eururo.2016.05.020 
14. Simpson JC, Moonesinghe SR, Grocott MPW et al (2015) Enhanced recovery from surgery in the UK: an audit of the enhanced recovery partnership programme 2009-2012. Br J Anaesth 115:560-568. https://doi.org/10.1093/bja/aev105

15. Lewis SJ, Andersen HK, Thomas S (2009) Early enteral nutrition within $24 \mathrm{~h}$ of intestinal surgery versus later commencement of feeding: a systematic review and meta-analysis. J Gastrointest Surg 13:569-575. https://doi.org/10.1007/ s11605-008-0592-X

16. Cerantola Y, Valerio M, Persson B et al (2013) Guidelines for perioperative care after radical cystectomy for bladder cancer: Enhanced Recovery After Surgery (ERAS ${ }^{\circledR}$ ) society recommendations. Clin Nutr 32:879-887. https://doi.org/10.1016/j. clnu.2013.09.014

17. Matulewicz RS, Brennan J, Pruthi RS et al (2015) Radical cystectomy perioperative care redesign. Urology 86:1076-1086. https:// doi.org/10.1016/j.urology.2015.09.001

18. Deibert CM, Silva MV, RoyChoudhury A et al (2016) A prospective randomized trial of the effects of early enteral feeding after radical cystectomy. Urology 96:69-73. https://doi.org/10.1016/j. urology.2016.06.045

19. Lewis SJ, Egger M, Sylvester P, Thomas S (2001) Early enteral feeding versus "nil by mouth" after gastrointestinal surgery: systematic review and meta-analysis of controlled trials. BMJ 323:773-776. https://doi.org/10.1136/bmj.323.7316.773

20. De Vries RR, Kauer P, Van Tinteren H et al (2012) Shortterm outcome after cystectomy: comparison of two different perioperative protocols. Urol Int 88:383-389. https://doi. org/10.1159/000336155

21. Marret E, Remy C, Bonnet F et al (2007) Meta-analysis of epidural analgesia versus parenteral opioid analgesia after colorectal surgery. Br J Surg 94:665-673. https://doi.org/10.1002/bjs.5825

22. Bochner BH, Dalbagni G, Sjoberg DD et al (2015) Comparing open radical cystectomy and robot-assisted laparoscopic radical cystectomy: a randomized clinical trial. Eur Urol 67:1042-1050. https://doi.org/10.1016/j.eururo.2014.11.043 